\title{
Can we Learn from Down Under How to Rise Up in E-Government? A Comparative Analysis of the Public Sector Competences in the German and Australian Higher Education Systems
}

\author{
Nadine Ogonek and Jörg Becker \\ University of Münster - European Research Center for Information Systems (ERCIS) \\ \{nadine.ogonek, joerg.becker\}@ercis.uni-muenster.de
}

\begin{abstract}
Australia has been voted world's second in the last two United Nations e-government surveys 2014 and 2016, despite the acknowledged difficulties that arise in terms of implementation because of its federal structure. Germany, having a similar federal structure, in contrast, only ranks $15^{\text {th }}$. The study at hand aims at eliciting, if this development can be ascribed to the higher public administration and e-government education landscape. By means of a content analysis, we examined 126 higher education study programmes with a link to the public sector in Australia and compared them to a similar study in Germany from the year 2015. Results show that there are indeed differences with respect to the delivered contents and the respective competences in Australia that might contribute to the different e-government development in the two countries: Higher levels of socio-technical courses and a more contextualised programme delivery in general are two of the main findings.
\end{abstract}

\section{Introduction}

The modernisation of public administrations worldwide is in full swing. Coming from a mere vision of policy makers around the globe "[...] to improve public services and democratic processes" [8], it is turning bit by bit into reality. Induced and enabled by "[...] the use of information and communication technologies [...] combined with organizational changes and new skills” [8], this modernisation process, known under the term electronic government (e-government) has started its success story. The European Commission ascribes great potential to this concept. In their e-government action plan 2016-2020 [9:2], e-government is said to not only contribute to a more efficient and effective service delivery by the reduction of administrative burdens throughout the European Union (EU), but also to be able to " $[\ldots]$ unlock further economic and social benefits for society as a whole."

A recent benchmark study, however, reveals that, even though in general public services are increasingly available in the EU with an online availability of $81 \%$ and an online usability of 83\%, not all European countries are developing equally $[4,10,11]$. According to [36:23] "[...] policy makers face a race between technology and education, and the winners will be those who encourage skill upgrading so that all can benefit from digital opportunities." This statement turns into a postulate amongst decision makers worldwide, given the growing realisation, that digitalisation is not just a temporary phenomenon, but a revolutionary intrusion that has already started and will keep on sustainably changing the world.

Yet, similar to some other European countries, especially Germany (DE) is still falling short of expectations [2,12]. Albeit ranging among the top performers (number five out of 138 countries) in the Global Competitiveness Index [37], Germany has problems improving its performance with regard to digitalisation due to the still stagnant adoption of egovernment. This keeps it from leveraging the benefits, e-government can offer, despite a high broadband penetration and the existence of digital skills $[1,2,10]$. One possible cause for this situation could lie in the federal structure of Germany, where “[...] eGovernment policies have to be implemented largely through coordination mechanisms between national, regional and local public authorities rather than simply being forced top-down by national authorities.” [10:66] Besides those coordination efforts, the federal structure especially in Germany is said to bring along a mass of different IT systems that need to become integrated and interoperable, "[...] which is probably unique in the world” [20]. Globally seen, though, it is Australia (AUS) with its federal system that is among the worldleading countries in e-government and keeps ranking second, in 2016 behind the United Kingdom (UK) and in 2014 behind the Republic of Korea (KOR) according to the E-Government Development Index. 
Germany, in contrast, is currently only at position 15 [33,34]. We chose Australia due to its similarity to Germany in terms of the political structure with a federal system and an equally independently operating educational system.

Many reasons could contribute to this diverging development. Next to political, economic, legal or cultural influences, the education in this particular area might also be a reason that accounts for this difference: "Successful digital transformation does not come from implementing new technologies but from transforming an organisation to take advantage of the possibilities that new technologies provide. Besides leading the change, this also requires that all people in an organisation - leadership, IT professionals, employees in other divisions - obtain the skills to embrace technology." [10:76f] Thus, an adequate preparation of the ones responsible for the implementation of egovernment, i.e. the public servants who are increasingly exposed to Information Technology (IT), is therefore crucial, because its success is highly dependent on the employees' skills and expertise $[7,15]$. Especially the socio-technical competences, which gain in importance in this regard, should take a centre stage. Yet, they have been identified as still underrepresented in public sector higher education curricula [14]. Hence, it seems to be promising to have a look at the higher education system in a better-ranked country with a similar political structure like Australia to potentially learn from this approach. A transfer of the possibly identified best practices to the higher education system in Germany might result in improved competences of the public servants and lead to a more purposeful e-government in Germany in the end.

Against this backdrop, the research questions, we want to answer in this paper, are:

(1) What competences are taught in the Australian public sector higher education and how do they differ from Germany?

(2) To what extent can Germany learn from this approach, given its current higher education landscape in the public sector?

As a basis for comparison, we replicated the study by [14], who examine the German higher education system in the area of e-government and set up a competence framework with necessary skills and knowledge.

The remainder of this paper is structured as follows: In the next section, we refer to related work in this context. In section 3, we describe the research methodology, followed by a presentation of the results in section 4 . In section 5 , we discuss our findings and conclude the study in section 6 with a short summary of the work done, also highlighting limitations as well as illustrating starting points for future research.

\section{Related work}

The study by [14], which serves as primary reference point, analyses 91 Bachelor- and Master study programmes of 55 German universities in the field of public administration and e-government. They first identify e-government as well as IT-related contents, classify their importance within the programmes and analyse the five thematic competence categories within the programmes (see Table 1). Those categories were previously derived by means of a literature review. In this context, a competence can be defined as a combination of work-related knowledge, skills and abilities held by an individual [25].

Table 1. Competence categories by [14]

\begin{tabular}{|l|l|}
\hline Category & $\begin{array}{l}\text { Exemplarily assigned knowledge, } \\
\text { skills, competences }\end{array}$ \\
\hline technical & $\begin{array}{l}\text { information technology skills; IS design } \\
\text { competence, information systems }\end{array}$ \\
\hline $\begin{array}{l}\text { socio- } \\
\text { technical }\end{array}$ & $\begin{array}{l}\text { e-government impact; technology and e- } \\
\text { government adoption; politics of e- } \\
\text { government; }\end{array}$ \\
\hline organisational & $\begin{array}{l}\text { e-government structures; organisational } \\
\text { design; process management }\end{array}$ \\
\hline managerial & $\begin{array}{l}\text { Business skills; project management, } \\
\text { financial management, performance } \\
\text { management; change management }\end{array}$ \\
\hline $\begin{array}{l}\text { political- } \\
\text { administrative }\end{array}$ & $\begin{array}{l}\text { e-policy competences; legal framework, } \\
\text { administrative workflows; public policy }\end{array}$ \\
\hline
\end{tabular}

Their findings reveal that most of the study programmes cover topics from all five thematic competence categories, whereas programmes that have a high number of courses in one topical direction, typically exhibit a lower number of courses in another category. Some study programmes either do not at all or only barely touch the socio-technical dimension. One of their main findings is that "[...] social scientific topics are mostly taught apart from technical topics so that questions and potentials of IT remain underappreciated" [14:2119]. Although all thematic topics are covered to some extent, a general understanding of the importance of the technical aspects, their application and influence on the public sector context is missing, which is what the sociotechnical category focusses on. A general classification of socio-technical knowledge is the following: Technologically-induced changes in organisations require a " $[\ldots]$ continuing recognition of the interaction that is taking place between technical, economic, organisational and social factors when systems are being designed and, afterwards, when they are being used by groups that need the data they can provide.” [22:132f] Public servants, who work at the interface between customer demands, public processes 
and laws as well as technical requirements are increasingly in need of this competence category, since “[...] although technology and organizational structures may change in industry, the rights and needs of all employees must always be given a high priority" [23:45].

By classifying the competences, which stem from very different disciplines, [14] put emphasis on the interdisciplinary environment, public servants need to be prepared for. Such a discipline-spanning set of competences can be crucial, since "e-Government projects might fail when neglecting their multidisciplinary, complex and unstructured reality." [27:46]

The identification and classification of competences as critical success factor in any organisational context has been extensively studied in academia. There are studies identifying necessary competences for specific professions, such as the study of [13], that classifies twelve competence categories for professionals in the field of Business Process Management. Similarly, [21] identify leadership competences for successful project managers. Other studies, such as $[18,19,32]$ recognise the impact of IT on the organisation and the employees' performance and acknowledge the need for more IT competences. Those studies, however, either focus purely on IT competences or target specific professions, which is why they are not suitable here, due to the public servant's diverse field of activity.

Competences in and for e-government and a focus on the education as basis for a sound public service delivery, though, have only recently gained in importance and still are not among the primary research interests [26,29,30,35]. There are few attempts that endeavoured to structure e-government education [e.g. ,16,17]. A similar situation repeats itself in practice. The topic seems to be of minor importance for the operational business of the public sector, since 'education' and 'skills' do not appear at all in the European Commission e-government action plan 2016-2020 [9].

Due to the absence of guiding frameworks and best practices, the analysis of curricula and module handbooks seems to be a valid approach to find out more about the offered and required competences for e-government scholars. A considerable number of studies follow this approach in order to elicit the offered courses with the ultimate aim of subsequently revealing the delivered competences.

In their study, [6], for example, compare e-business programmes to analyse how these programmes are performing and which gaps can be revealed with regard to the industry demand and needs. They use a content analysis of business school websites to identify the offered programmes. In a similar vein, [7] take a closer look at the international education landscape to investigate the degree to which programmes build the relevant competences for the formation of a Government Chief Information Officer. For this purpose, they analyse online databases and websites of existing programmes and universities around the world. In another study, [3] use Information Systems (IS) education concepts and course structures to develop a framework to counteract the IS skills deficiency in South Africa.

\section{Method}

\subsection{Data collection}

In order to identify the relevant competences in the area of public administration, we first did an open online search to find suitable study programmes in the public sector in Australia. Then, we examined the publicly available module handbooks from the respective university websites, where we always took the latest version, if more than one were available. We based our search on three main websites. The first website, www.australianuniversities.com.au, includes an overview with undergraduate and postgraduate study courses in the field of (public) administration. We also searched the Australian study portals www.bachelorsportal.eu and www.mastersportal.eu, using the search terms "public administration”, "public management" and "e-government”. Lastly, we also had a look at the university webpages, identified through the website search, to see if there were relevant study programmes that had not been captured by the previous search. This analysis, conducted in February and March 2017, yielded 126 study programmes in total with different degrees including Bachelor (B) and Master programmes (M), as well as diplomas (D) and certificates (C), offered by 31 universities spread across Australia (see Table 2).

\subsection{Data cleansing}

Once the data collection with the basic information containing the study programme's name and degree as well as a short content description was completed, and the learning outcomes as well as an overview of all the courses were extracted, we cleansed the data. This was necessary, because several hits turned out to be less suitable for the analysis. First of all, we decided to only include full study programmes culminating in a Bachelor's or Master's degree, thus omitting all those that offer diplomas or certificates in order to safeguard the comparability with the study of [14], where those 
degrees only played a minor role. This eliminated 37 study programmes. Then, we also had a closer look at the contents of the programmes by studying the detailed course descriptions and the expected learning outcomes. We eliminated two more programmes, because of the limited information on the complete programme. In those two cases, only the majors were exemplified. Furthermore, we wanted to have a picture of the current education landscape in this area and therefore focussed on courses that were available and offered at the time of the search, thus excluding all those that were currently unavailable.

Another 52 study programmes were left out because our analysis aimed at identifying study programmes that are closely related to the administrative work in a public body. Almost all those programmes targeted the health sector like the Master of Health Services Management offered by Monash University, exhibiting a rather medical focus, tailored to the special needs of the health care sector. This cleansing in the end led to a final set of 35 study programmes from 15 universities, all coming from the social sciences with a broad range of specialisations, such as economics, management, business, politics or policy. Those programmes are highlighted in grey in Table 2.

Table 2. Analysed university programmes

\begin{tabular}{|l|r|r|r|r|r|}
\hline Study Programmes & Total & B & M & D & C \\
\hline Curtin College & 1 & 0 & 0 & 1 & 0 \\
\hline University of Canberra (UC) & 10 & 4 & 3 & 0 & 3 \\
\hline Flinders University (FU) & 20 & 2 & 7 & 3 & 8 \\
\hline Australian Catholic University & 4 & 0 & 2 & 1 & 1 \\
\hline Griffith University (GU) & 3 & 0 & 2 & 0 & 1 \\
\hline Monash University (MonU) & 3 & 0 & 2 & 0 & 1 \\
\hline $\begin{array}{l}\text { Australian National University } \\
\text { (ANU) }\end{array}$ & 13 & 2 & 11 & 0 & 0 \\
\hline University of Sydney (US) & 5 & 1 & 2 & 1 & 1 \\
\hline University of Newcastle & 1 & 0 & 1 & 0 & 0 \\
\hline University of Tasmania (UT) & 1 & 0 & 1 & 0 & 0 \\
\hline University of Wollongong & 2 & 1 & 0 & 0 & 1 \\
\hline La Trobe University & 3 & 0 & 2 & 0 & 1 \\
\hline Murdoch University (MuU) & 6 & 1 & 3 & 2 & 0 \\
\hline University of Melbourne (UM) & 5 & 0 & 4 & 0 & 1 \\
\hline $\begin{array}{l}\text { University of Western Australia } \\
\text { (UWA) }\end{array}$ & 4 & 0 & 4 & 0 & 0 \\
\hline $\begin{array}{l}\text { University of New South Wales } \\
\text { (NSWU) }\end{array}$ & 7 & 2 & 4 & 0 & 1 \\
\hline University of South Australia & 1 & 0 & 1 & 0 & 0 \\
\hline
\end{tabular}

\begin{tabular}{|l|r|r|r|r|r|} 
University of Technology & 4 & 0 & 2 & 1 & 1 \\
\hline $\begin{array}{l}\text { Queensland University of } \\
\text { Technology }\end{array}$ & 3 & 0 & 0 & 0 & 3 \\
\hline $\begin{array}{l}\text { Charles Darwin University } \\
\text { (CDU) }\end{array}$ & 1 & 0 & 1 & 0 & 0 \\
\hline University of Adelaide & 2 & 0 & 2 & 0 & 0 \\
\hline $\begin{array}{l}\text { Curtain University of } \\
\text { Technology }\end{array}$ & 2 & 0 & 2 & 0 & 0 \\
\hline Deakin University (DU) & 4 & 3 & 1 & 0 & 0 \\
\hline Western Sydney University & 1 & 0 & 1 & 0 & 0 \\
\hline Bond University & 1 & 0 & 1 & 0 & 0 \\
\hline $\begin{array}{l}\text { Carnegie Mellon University } \\
\text { Australia (CMU) }\end{array}$ & 3 & 0 & 3 & 0 & 0 \\
\hline University of Queensland (UQ) & 3 & 2 & 1 & 0 & 0 \\
\hline Charles Sturt University & 7 & 1 & 1 & 1 & 4 \\
\hline $\begin{array}{l}\text { Swinburne University of } \\
\text { Technology }\end{array}$ & 1 & 1 & 0 & 0 & 0 \\
\hline $\begin{array}{l}\text { University of Southern } \\
\text { Queensland }\end{array}$ & 4 & 4 & 0 & 0 & 0 \\
\hline Southern Cross University & 1 & 1 & 0 & 0 & 0 \\
\hline Total (all programmes) & $\mathbf{1 2 6}$ & $\mathbf{2 5}$ & $\mathbf{6 4}$ & $\mathbf{1 0}$ & $\mathbf{2 7}$ \\
\hline
\end{tabular}

\subsection{Analysis of the study programmes}

Traditionally, in the social science research, the analysis of unstructured data in the form of textual documents had to be done manually. The coding therefore was very costly and time-consuming as well as prone to limitations and biases due to large data sets, amongst others things [28].

Computer-supported qualitative data analysis software such as NVivo or QCA map can support this coding process, for example by enabling the direct comparison of coded data. We estimated NVivo as suitable software to analyse the 35 study programmes and based our analysis on the qualitative content analysis by [24]. Then, we deductively categorised the documents in order to analyse them quantitatively afterwards. As earlier described, for this purpose, we used the publicly available online module handbooks of the study programmes and extracted the information given on the course contents as well as the course specific learning outcomes. The predefined elements that constituted the deductive categories were grounded in the categorisation of e-government knowledge, skills and competences, i.e. technical, socio-technical, organisational, managerial and political-administrative competences, developed by [14], see Table 1 . We followed their general classification scheme and only slightly extended the comprehension of one category in consideration of the material at hand. This adjustment concerns the socio- 
technical dimension. Since there were hardly any mentions of the term "e-government", we defined the socio-technical competence category as relating to the application of technology in a given administrative context. Courses that target those competences are, e.g., "New models for governance and strategy, innovation, decentralization" (ANU) or "Leading Innovation” (UM).

Next to the obligatory programme courses, we also included all study electives, whereof always a certain number was mandatory to be chosen. Two universities form an exception in this regard: The University of Sydney (US) and the University of Melbourne (UM) offer a large number of university-wide electives, constituting a total of 110 and 87 electives respectively, out of which a maximum of three (US) or five (UM) were to be selected. Since those courses were very wide-reaching and not necessarily related to the public sector, we only included the mandatory courses in the case of the US and, in the case of the UM, we opted for selecting the electives that were exhibited in the example study plan on the study programme's website.

Given the fact that one course oftentimes does not only cover a single competence, due to the context in which it is delivered, we decided to allow the repeated classification of one course into different competence categories. This is also the reason why the number of appearing competences is a lot higher than the number of actual courses. The courses were only classified into one or more competence categories, if either the course title, the course description or the learning outcomes (explicitly) referred to the competence category.

We discussed the validity and feasibility of this overall approach of classification in a small group of egovernment researchers before its implementation.

\section{Results}

\subsection{General results}

We analysed a total of 515 courses belonging to the 35 study programs, out of which six are programmes culminating in a Bachelor's degree and 29 in a Master's degree. Four programmes are executive programmes, thus targeted at the education of public servants already working in the public sector: The executive Master of Public Administration. The majority of courses is related to the politicaladministrative competence category with an absolute number of 378 (40\%), followed by the managerial competence category with 349 courses (36\%) (Figure 1 ). The course number of a programme ranks between six courses in the case of the Master of Public Policy
(UT) and 59 courses (including a broad choice of electives) in the Master of Public Policy or the Master of Public Policy in Economic Policy, both offered by ANU.

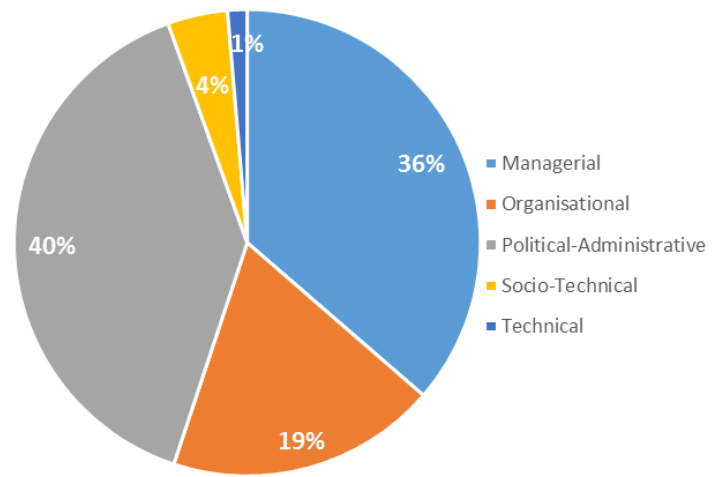

Figure 1. Distribution of competences among all offered courses

The average number of courses within a programme is around 27.5 courses. $19 \%$ of the courses target organisational competences, thus ranking third most often. Surprisingly, the technical competence category scores lowest with only $1 \%$ (13 in absolute numbers) of the courses that explicitly deal with the use or application of IT skills and Information Systems. Even the socio-technical courses with $4 \%$ (40 in absolute numbers) surpass them.

Concerning the competence distribution within the single programmes, it becomes obvious that in most of the 35 programmes all competence categories are represented by some kind of course(s).

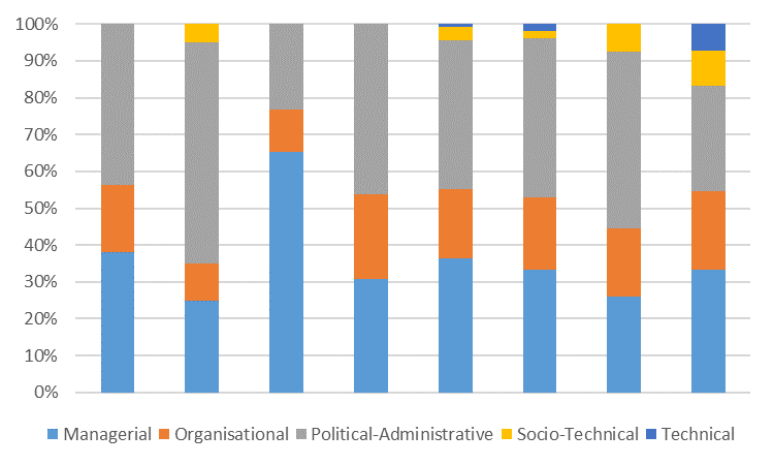

1: (FU) B: Government and Public Management| 2: (DU) B: Politics and Policy Studies| 3: (UQ) M: Economics and Public Policy| 4 (US) M: Public Administration| 5: (ANU) M: Public Policy in Dev. Policy| 6: (MuU) M: Public Policy and Management| 7: (DU) M: Politics and Policy| 8: (UC) B: Public Administration

Figure 2. Distribution of competences in selected study programmes

Exceptions with only four competence categories, lacking the technical competence category, are the 
Bachelor of Politics and Policy Studies (DU), the Master of Politics and Policy (DU), the Master of Public Administration (FU), the Master of Public Policy and Governance (NSWU), the Masters of Public Policy and Management (MonU, UM) and the Master of Public Policy (CDU). Seven further programmes only include three of the competence categories and completely neglect the technical and socio-technical competence categories. Those programmes are the Bachelor of Government and Public Management (FU), the Master of Economics and Public Policy (UQ), the Master of Public Administration (International) (UT), the Masters of Public Administration (GU, UM, US) and the Master of Public Policy (UT). Figure 2 exhibits a selection of eight different programmes to illustrate the heterogeneity in their composition concerning the different competence categories.

\subsection{Comparison with the study by [14]}

At first sight, there does not seem to be a big difference between delivered competences in the higher education landscape concerning e-government and public administration in Germany and Australia. Only a more thorough analysis reveals the nuanced peculiarities, which we outline in the following:

[14] categorise the different competences on a one to four scale from not to strongly manifested. To safeguard the comparability between the two studies, we summed up the first study's levels three and four ("existent" and "strong”), since we only classified the categories as being existent or not. This is also the reason why the percentages of the German scores appear higher than the Australian scores (see Table 3).

Table 3. Results of the comparison

\begin{tabular}{|l|c|c|}
\hline \multicolumn{1}{|c|}{ Category } & DE (\%) & AUS (\%) \\
\hline managerial & 69 & 36 \\
\hline organisational & 67 & 19 \\
\hline political-administrative & 84 & 40 \\
\hline socio-technical & 27 & 4 \\
\hline technical & 13 & 1 \\
\hline
\end{tabular}

As a result, it turns out that all of the competence categories are represented within the study programmes with courses targeting politicaladministrative competences as strongest thematic focus, followed by courses targeting managerial competences and then courses targeting organisational competences. Socio-technical and technical competences are the competences at the rear end in both countries. A difference to Germany is that "[...] social scientific topics are mostly taught apart from technical topics, so that questions and potentials of IT remain underappreciated” [14:2119]. We cannot confirm this statement here, since among the 35 programmes, only seven do not offer any sociotechnical courses: The Bachelor of Government and Public Management (FU), The Master of Economics and Public Policy (UQ), both Master programmes offered by UT, and the Master of Public Administration, offered by GU, UM and US. Strikingly though, out of the 13 courses, classified as technical, eleven were also tagged as socio-technical, which leaves only two that exclusively focus on the technical body without considering its application environment. Even though this number still is to be considered quite low, its integration seems to be more profound and on a broader basis. Furthermore, [14] mainly find a low degree of interrelation between the different thematic foci and hence also a minor integration of the targeted competences. This outcome cannot be confirmed in the Australian case, either: The majority of courses offered tap more than one competence category - only $21 \%$ percent of the managerial courses, $1 \%$ of the organisational courses, $27 \%$ of the politicaladministrative courses and $0,1 \%$ of the technical courses are classified as belonging exclusively to one single category. Beyond that, socio-technical courses are not at all to be found as only belonging to this category. 33\% of all courses target the managerial and political dimension and $27 \%$ target managerial and organisational competences and equally $27 \%$ can be assigned to organisational and political-administrative courses, respectively. $13 \%$ of the courses include managerial, organisational and politicaladministrative contents and $2 \%$ even target four categories, i.e. all categories except of the technical category. What we could confirm, though, is that technical courses remain largely disconnected from political-administrative topics: Out of all offered technical courses, only two also address politicaladministrative issues.

A promising example of a study programme in this regard is the Master of Science in Public Policy and Management (Digital Transformation and Analytics), offered by CMU, since it offers a more interdisciplinary approach, combining all the different competences in a more balanced manner, as can be seen in Figure 3. First, all competence categories are represented by a decent number of respective courses. Second, the programme offers a course, particularly addressing the issues faced by public administrations due to the rising degree of digital processes and a changing work environment, namely Digital Transformation. The course's goal is "[...] to integrate technological and managerial aspects of information technology." 


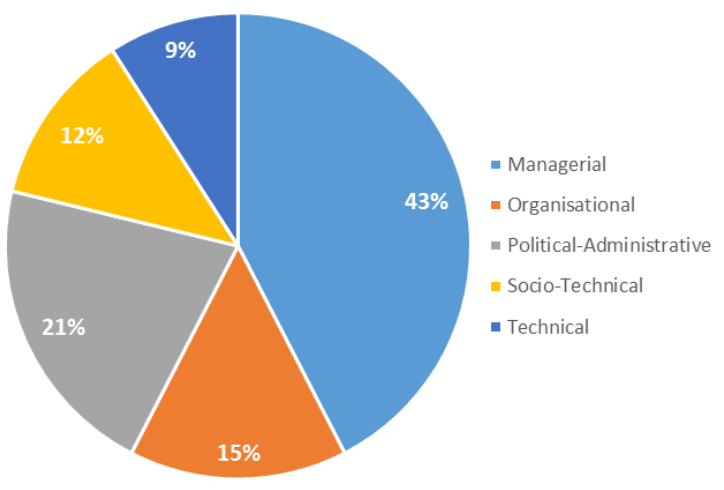

Figure 3. Distribution of competences in the Master of Science in Public Policy and Management (CMU)

Another good example of a course that bridges the gap between different competence categories, belonging to all Master programmes offered by ANU, is the course Comparative Public Sector Management. It offers a broad introduction into the public administration context including the historic development as well as current and future topics like reforms in the public sector and their impact(s) on governance and networks, community engagement and e-government.

\subsection{Further findings}

Another very interesting finding is the existence of an inner and outer Australian border-spanning executive master programme: The Executive Master of Public Administration, offered by the Australia and New Zealand School of Government (ANZSOG). A network of 15 Australian and New Zealand universities offers this programme, with its distinctive feature lying within the eight offered core courses that are taught at every member university:

- Delivering Public Value

- Managing Public Sector Organisations

- Government in a Market Economy

- Designing Public Policies and Programs

- Decision-making Under Uncertainty

- Governing by the Rules

- Leading Public Sector Change

- Work-based Project

This two-year programme is designed: "[...] to equip high-performing public sector managers with the fresh ideas, skills and expertise they need to deliver value to the communities they serve" [31]. Besides those eight core courses, every university offers its own electives, whereof one must be chosen in the area of public sector financial management. Looking at the competence structure of this programme, it offers a mix of mainly managerial, organisational and political-administrative courses, enlarged by fewer socio-technical and one technical course, thus following approximately the same distribution as the other programmes.

In this programme, also the mandatory work-based project arose our attention, where students get the chance to apply their knowledge in a practical realworld setting. This is also something, we found in many of the 35 analysed programmes. Eight of the 15 institutions providing these programmes explicitly offered internships or work placements, whereof five included them as mandatory courses and three as electives.

Lastly, we found that the term "e-government" did not at all appear in any programme title of all analysed programmes, nor did it appear as course name. If mentioned at all, it appeared within the course descriptions or the learning outcomes, sometimes not mentioning the name either, but rather describing the concept.

\section{Discussion}

Summing these results up, we can say that structurally there are hardly any differences between the German and Australian higher education system concerning the public sector. The courses offered mainly target the same five competence categories.

However, there are some differences that are more subtle in nature. Besides the higher availability of courses that explicitly target socio-technical competences, the courses seem to be more interrelated and more contextualised. Contents are barely taught independently, but are put into the context of the peculiar situation of public administrations, addressing the institutional landscape as well as the particular surrounding conditions that shape the structure and functioning of public bodies. In doing so, they address a single topic from a set of possible perspectives, not limited to a one-sided, e.g. legal perspective.

Furthermore, practical experience in real-world public settings as well as a broad choice of thematic foci seem to be of higher significance in Australia than in Germany. If in Germany the conclusion drawn from this analysis is that "[...] the public administration has no clear image about what kind of educated staff they need in the context of e-government" [14:2121], it seems that the picture in Australia is clearer: The competences need an interdisciplinary perspective on the issues the public sector is facing now. The courses offered in this sphere seem to be better aligned to this demand. 
It is also striking that the term e-government does not seem to bear great importance for the categorisation of study programmes or courses, since it is hardly used, which might have different reasons. Either the concept is not broadly known under this name, despite its usage on governmental websites, or it is more important to describe its contents to make it more feasible for the outside world.

Generally, it has to be taken into consideration that we only had a limited look at the higher education landscape in the public sector in Australia. We did not consider other education paths, that surely equally exist, like an apprenticeship system, which might take the same or a completely different approach. A deeper analysis of the education system in Australia as such would also help to shed light on this matter: Is the education organised in a way that students are equipped with competences like problem-solving and the consideration of different perspectives right from the start? Is there a greater importance attached to practical or applied knowledge?

Moreover, the burdens of implementing such programmes in a federal system might not be equally high in the two countries. The results show that a joint executive master programme like ANZSOG that also integrates practitioner's knowledge is not only possible beyond the autonomously operating states and territories. It is also enabled beyond country borders, providing for a more synchronised content- and competence delivery and creating a joint knowledge basis. A higher degree of knowledge sharing and exchange possibly enhances best practice sharing, learning and signifies a better understanding and service delivery. "Sharing knowledge and information is also an important factor [...] to improve the quality of services to the public, government agencies need to share their most effective knowledge-sharing practices by collaborating, both internally, within agencies, and externally, with agencies of similar functions." [19:370]

\section{Conclusion and Outlook}

Summary. In this study, we compared the Australian and German higher education landscape in the public sector to find out more about the similarities and especially the differences of the offered competences in the two federal countries. In doing so, we wanted to examine whether Australia's prescribed success in e-government can be ascribed to a difference in their higher education system. By means of a content analysis, we could identify a number of differences. Those differences are not fundamental in nature, but still offer some insights and best practices that might lead to a better e-government development in the end. We found out that the Australian system certainly also has some shortcomings, as there are study programmes that ignore the socio-technical and/or technical perspective altogether. Yet, there are also some programmes as well as special courses that exhibit better-integrated contents, which also contextualise the perspectives that need to be addressed in the public sector. Especially the socio-technical perspective is better and more broadly covered, which is important, because "[...] organizational objectives are best met not by the optimization of the technical system and the adaptation of a social system, but by the joint optimization of technical and the social aspects" [5:786]. Overall, there seems to be a better understanding of what mix of competences is needed to be able to successfully navigate through the diverse and multidisciplinary public sector environment.

The ANZSOG programme that bridges national and international educational gaps is another element that signifies a better higher education in this sector by means of a collaborative approach, conveying identical contents across borders. This could serve as a role model for Germany for the sake of a better egovernment education that meets the demands and requirements, leading to an improved public service delivery.

Limitations. This study is, of course, not without limitations. First, we only had a look at the educational landscape for a very short time during the search of programmes in spring 2017 and therefore only integrated those programmes and courses that were available at that time. Additionally, we concentrated on selected websites, which might have led to an incomplete list of study programmes. Then, we focussed on examining the higher education programmes, neglecting the education that might exist beyond or in parallel. Furthermore, we did not consider possible developments that might have taken place in the German system since the study by [14] in 2015. Newer study programmes that might exist now are not incorporated. Lastly, the assignment of the courses to specific competence categories might have been biased or incorrect due to the limited information given on the websites.

Nevertheless, this study offers some considerable implications for research and for practice: Institutions offering e-government education of any kind should rethink the course structure and check the availability of socio-technical as well as interrelated courses that reflect the situation and issues of today's public administrations, thus being closer to their reality. New courses and study programmes need to be thought of and developed that better integrate the different multidisciplinary perspectives that come into play in 
the public administration everyday life. Some of the Australian study programmes could serve as role model in this regard. With the help of more international comparative studies, a classification scheme for necessary competences in the egovernment domain can be developed.

For research, due to the fast changing environment technical innovations cause, a constant analysis of the prerequisites and needed competences to early identify new developments should be pursued. This study is only a first step to investigate what the public sector education sphere looks like and to identify best practices.

Outlook. Future research should broaden the perspective and examine other kinds of educational paths as well as other countries that score high in egovernment, too. A comparison with countries like e.g. the UK or the Republic of Korea could help to receive more insights into the international constitution of egovernment education and identify further best practices. Furthermore, also the German higher education system should be monitored continuously to see in how far the education is changing over time.

Another option is to take a more nuanced look at the faculties to understand why programmes are designed the way they are and possibly give recommendations towards a suitable composition of courses. Moreover, it would be insightful to monitor the development of programmes over time to derive the degree of importance of the higher education in the public sector (in terms of study programme numbers and the number of graduates actually working in public bodies afterwards) as well as to learn about how they evolve content wise.

We wanted to learn about the different structures in the two countries and inspire fellow scholars to do research in an area that opens for several further areas of investigation like the demand perspective of higher education programmes, addressing questions, such as: Why do international students consider studying in a country that is completely different to their home country's structures? This perspective was outside the scope of this study.

By comparing the educational systems, we aimed at answering the two initially posed research questions. Concerning question 1 , we found out that the higher education in Germany and Australia are structurally congruent, offering (almost) the same types of courses and in doing so, addressing nearly the same contents. Differences only become visible when investigating the composition of courses and their way of delivery from a closer angle. Concerning research question 2, we can conclude that Germany can learn about the way on how competences can be delivered in a more contextualised manner, integrating the different perspectives, public servants are confronted with. A mixture of disciplines such as politics, law, management and technology, as shown by the different mandated competences, is needed. Australia offers a number of programmes with courses that seem closer to the reality of public administrations nowadays and therefore better prepare (future) public servants for their work in a changing environment. Those are valuable insights that can help to improve the education in the public sector and ultimately lead to a better and more effective public service delivery that is at the heart of the e-government vision.

\section{References}

[1] Akkaya, C., Obermeier, M., Wolf, P., and Krcmar, H. Components of Trust Influencing eGovernment Adoption in Germany. Electronic Government: Proceedings of the 10th IFIP WG 8.5 International Conference, EGOV 2011, (2011), 88-99.

[2] Akkaya, C., Wolf, P., and Krcmar, H. A Comprehensive Analysis of E-Government Adoption in the German Household. 11th International Conference on Wirtschaftsinformatik, (2013), 15251539.

[3] Breytenbach, J. and De Villiers, C. Increasing the Quality and Quantity of Tertiary-Level Information Systems Students: A Graduate Development Framework. Information Technology for Development 21, 2 (2015), 178-195.

[4] Carter, L., Weerakkody, V., Phillips, B., and Dwivedi, Y.K. Citizen Adoption of E-Government Services: Exploring Citizen Perceptions of Online Services in the United States and United Kingdom. Information Systems Management 33, 2 (2016), 124140.

[5] Cherns, A. The Principles of Sociotechnical Design. Human Relations 29, 8 (1976), 783-792.

[6] Davis, S., Siau, K., and Dhenuvakonda, K. A fitgap analysis of e-business curricula vs. industry needs. Communications of the ACM 46, 12 (2003), 167-177.

[7] Estevez, E. and Janowski, T. Landscaping

Government Chief Information Officer Education.

Proceedings of the 46th Hawaii International Conference on System Sciences (HICSS-46), IEEE (2013), 1684-1693.

[8] European Commission. eGovernment. 2006. http://bit.ly/1UyXy1U.

[9] European Commission. EU eGovernment Action Plan 2016-2020 - Accelerating the Digital

Transformation of Government. 2016.

[10] European Commission. eGovernment Benchmark 2016 A turning point for eGovernment development in Europe? Luxembourg, 2016. 
[11] Gilbert, D., Balestrini, P., and Littleboy, D. Barriers and benefits in the adoption of e-government. International Journal of Public Sector Management 17, 4 (2004), 286-301.

[12] Goings, D., Young, D., and Hendry, S.H. Critical Factors in the Delivery of e-Government Services : Perceptions of Technology Executives. Communications of the International Information Management Association 3, 3 (2003), 1-15. [13] Gorbacheva, E., Stein, A., Schmiedel, T., and Müller, O. The Role of Gender in Business Process Management Competence Supply. Business and Information Systems Engineering (BISE) 58, 3 (2016), 213-231.

[14] Hunnius, S., Paulowitsch, B., and Schuppan, T. Does E-Government education meet competency requirements? An analysis of the German university system from international perspective. Proceedings of the 48th Hawaii International Conference on System Sciences (HICSS-48), IEEE (2015), 2116-2123. [15] Hunnius, S. and Schuppan, T. Competency requirements for transformational e-government. Proceedings of the 46th Hawaii International Conference on System Sciences (HICSS-46), IEEE (2013), 1664-1673.

[16] Janowski, T., Cellary, W., and Davies, J. Introduction to Electronic Government Education , Training and Professionalization. Proceedings of the 46th Hawaii International Conference on System Sciences (HICSS-46), IEEE (2013), 1662-1663.

[17] Janowski, T., Estevez, E., and Ojo, A. Conceptualizing Electronic Governance Education. Proceedings of the 45th Hawaii International Conference on System Sciences (HICSS-45), IEEE (2012), 2269-2278.

[18] Kim, G., Shin, B., Kim, K.K., and Lee, H.G. IT Capabilities, Process-Oriented Dynamic Capabilities, and Firm Financial Performance. Journal of Association for Information Systems 12, 7 (2011), 487517.

[19] Kim, S. and Lee, H. The impact of organizational context and information technology on employee knowledge-sharing capabilities. Public Administration Review 66, 3 (2006), 370-385.

[20] Kubicek, H. and Wind, M. Integrated EGovernment in a Federal State Structure? Challenges on the Way to Effective Administrative Procedures. 2004. http://bit.ly/2xD1lSA.

[21] Müller, R. and Turner, R. Leadership competency profiles of successful project managers. International Journal of Project Management 28, 5 (2010), 437-448. [22] Mumford, E. A Socio-Technical Approach to Systems Design. Requirements Engineering 5, 2 (2000), 125-133.
[23] Mumford, E. Socio-technical Design: An unfulfilled promise or a future opportunity? In B. R., S. J. and D. J.I., eds., Organizational and Social Perspectives on Information Technology. Springer, Boston, MA, 2000, 33.46.

[24] Myers, M.D. and Newman, M. The qualitative interview in IS research: Examining the craft. Information and Organization 17, 1 (2007), 2-26. [25] Nordhaug, O. Human capital in organizations: competence, training, and learning. Oxford University Press, Oxford, 1993.

[26] Ogonek, N. The Tale of e-Government: A Review of the Stories that Have Been Told So Far and What is Yet to Come. Proceedings of the 50th Hawaii International Conference on System Sciences (HICSS50), IEEE (2017), 2468-2477.

[27] Puron-Cid, G. Interdisciplinary application of structuration theory for e-government: A case study of an IT-enabled budget reform. Government Information Quarterly 30, (2013), 46-58.

[28] Quinn, K.M., Monroe, B.L., Colaresi, M., Crespin, M.H., and Radev, D.R. How to analyze political attention with minimal assumptions and costs. American Journal of Political Science 54, 1 (2010), 209-228.

[29] Scholl, H.J. Electronic Government Research: Topical Directions and Preferences. Electronic Government: Proceedings of the 12th IFIP WG 8.5 International Conference, EGOV 2013, (2013), 1-13. [30] Scholl, H.J. The EGOV Research Community: An Update on Where We Stand. Electronic Government:

Proceedings of the 13th IFIP WG 8.5 International Conference, EGOV 2014, (2014), 1-16.

[31] The Australia and New Zealand School of Government. Executive Master of Public Administration. 2017.

[32] Tijdens, K. and Steijn, B. The determinants of ICT competencies among employees. New Technology, Work and Employment 20, 1 (2005), 60-73. [33] United Nations. United Nations E-Government Survey 2014 - E-Government for the future we want. New York, 2014.

[34] United Nations. United Nations E-Government Survey 2016 - E-Government in support of sustainable development. New York, 2016.

[35] Wimmer, M.A., Codagnone, C., and Janssen, M. Future e-government research: 13 research themes identified in the eGovRTD2020 project. Proceedings of the 41st Hawaii International Conference on System Sciences (HICSS-41), IEEE (2008), 1-11.

[36] World Bank. World Development Report: Digital Dividends. Washington, D.C., 2016.

[37] World Economic Forum. The Global Competitiveness Report 2016-2017. Geneva, 2016. 